\title{
A CLINICAL STUDY ON INCIDENCE OF RETINOPATHY OF PREMATURITY CHANGES IN PRETERM INFANTS AND ASSOCIATED RISK FACTORS IN A TERTIARY CENTRE
}

Sneha R${ }^{1}$, Poornima Shankar ${ }^{2}$

HOW TO CITE THIS ARTICLE:

Sneha R, Poornima Shankar. "A Clinical Study on Incidence of Retinopathy of Prematurity Changes in Preterm Infants and Associated Risk Factors in Tertiary Centre". Journal of Evolution of Medical and Dental Sciences 2014; Vol. 3, Issue 10, March 10; Page: 2603-2607, DOI: 10.14260/jemds/2014/2180

ABSTRACT: OBJECTIVE: This is a hospital based, prospective clinical study on incidence of retinopathy of prematurity changes in preterm infants and associated risk factors. METHODS: Neonates with gestational age $<37$ wks and/ or birth weight $\leq 2500$ gms born over one year period were examined by indirect ophthalmoscopy between 2 to 4 weeks after birth, and followed up till retinal vascularization was complete. Maternal and neonatal risk factors were noted and data analyzed by statistical package SPSS-15. RESULTS: 100 babies were thus examined. The overall incidence of retinopathy of prematurity was 40\%, 22\%in babies' $\leq 34 \mathrm{wks}$ of gestation and $52 \%$ in babies with a birth weight1500-2000g. Majority were in stage 2 . Gestational age $(<32$ weeks), Birth weight $(<1500 \mathrm{~g})$, RDS, surfactant therapy, PDA were found to be risk factors. CONCLUSION: Meticulous fundus examination with indirect ophthalmoscopy in all preterm babies with gestational age $<37$ weeks and birth weight $\leq 2500 \mathrm{gms}$ is essential noninvasive method for early detection of ROP and its progression. Screening should be intensified in the presence of factors like RDS, oxygen administration and presence of PDA.

KEYWORDS: ROP - Retinopathy of prematurity, RDS - Respiratory distress syndrome.

INTRODUCTION: Retinopathy of prematurity (ROP) is an important cause of preventable blindness in children. ${ }^{1}$ Recent advances in neonatal care in the last decade, have improved the survival rates for premature infants. Consequently, the incidence of ROP has increased in parallel. Early identification of retinal damage and the institution of appropriate treatment prevent blindness and offer child better overall development. ${ }^{2}$

ROP is characterized by abnormal neovascular development in the retina of premature infants. This causes a fractional retinal detachment, which is the main cause of visual impairment and blindness in ROP. ${ }^{3}$

Three factors have shown consistent and significant association with ROP: low gestational age, low birth weight and prolonged exposure to supplementary oxygen following delivery. ${ }^{4}$

Other putative risk factors include mechanical ventilation, ${ }^{5}$ sepsis, ${ }^{6}$ intra ventricular hemorrhage, ${ }^{4}$ surfactant therapy, ${ }^{7}$ anemia, ${ }^{8}$ frequent blood transfusions, ${ }^{8}$ and apnea. ${ }^{8}$ The precise roles of these factors individually in the progression of the disease have not yet been determined.

MATERIALS AND METHODS: This prospective cohort study was conducted in NICU in cooperation between the Departments of Neonatology and Ophthalmology. 100 preterm neonates were screened to be included in the study. 100 preterm infants admitted to the NICU from January 2011 to December 2011, with a gestational age of less than 36 weeks and a birth weight of $<2500$ g.Neonates 
who died before the first ophthalmological and Infants with congenital anomalies, chromosomal abnormalities, inborn errors of metabolism were excluded from the study $(n=10)$.

HISTORY: Perinatal history; presence of risk factors as prematurity, sepsis, perinatal asphyxia, RDS and hyperbilirubinemia.

Clinical Examination, gestational age was assessed by new Ballard scoring.

Local Eye Examination: infants were examined at 1-2 weeks intervals from the 4th postnatal week onwards. The eyes were dilated with a combination of cyclopentolate $0.2 \%$ and phenylephrine $1 \%$ eye drops applied 1 hour before the examination.

Indirect ophthalmoscopy with a 28 dioptre lens was performed with speculum and scleral depression. Retinal examination was done using ret cam.

ROP was classified by location on the retina (zone 1-3), and severity (stage 1-5), according to the International Committee for Classification of ROP.11 All patients diagnosed with stage 3 ROP with plus disease were treated with laser photocoagulation. Follow up was done until full vascularization of retina.

The prenatal variables were gestational age, birth weight, sex and mode of delivery. The afterbirth variables were RDS, oxygen therapy, phototherapy for jaundice, frequency of blood transfusions, sepsis, hypotension, intraventricular hemorrhage and patent ductus arteriosus.

STATISTICAL ANALYSIS: Data were analyzed by the Statistical Package for the Social Sciences (SPSS for windows, version 13.0). Descriptive statistics included the mean and standard deviation for numerical variables, and the percentage of different categories for categorical variables. The incidence rate of ROP was described in simple proportion. Group comparisons were done by the chisquared $\left(\chi^{2}\right)$ test or Fisher's exact test for categorical variables. A logistic regression model was performed and the adjusted OR (95\% CI) was obtained for the risk factors which had been shown to be significant in the univariate analysis. A probability (P) of less than 0.05 was considered significant.

\section{RESULTS:}

\begin{tabular}{|c|c|c|}
\hline Incidence of ROP & Number of babies & $\mathbf{\%}$ \\
\hline Absent & 54 & 60.0 \\
\hline Present & 36 & 40.0 \\
\hline Total & $\mathbf{9 0}$ & $\mathbf{1 0 0 . 0}$ \\
\hline
\end{tabular}

Table 1: Distribution of incidence of ROP of patients studied

\begin{tabular}{|c|c|c|}
\hline Stage & Number of babies $(\mathbf{n = 9 0 )}$ & $\mathbf{\%}$ \\
\hline Stage 0 & 54 & 60 \\
\hline Stage I & 12 & 13.3 \\
\hline Stage II & 21 & 23.3 \\
\hline Stage III & 3 & 3.3 \\
\hline
\end{tabular}

Table 2: Distribution of stage of patients studied 
ORIGINAL ARTICLE

\begin{tabular}{|c|c|c|c|c|c|}
\hline \multirow{3}{*}{ Neonatal complications } & \multicolumn{4}{|c|}{ ROP } & \multirow{3}{*}{$P$ value } \\
\hline & \multicolumn{2}{|c|}{$\begin{array}{l}\text { Absent } \\
(n=54)\end{array}$} & \multicolumn{2}{|c|}{$\begin{array}{c}\text { Present } \\
(n=36)\end{array}$} & \\
\hline & No & $\%$ & No & $\%$ & \\
\hline 1.RDS & 4 & 7.4 & 13 & 36.1 & $0.001^{* *}$ \\
\hline 2.Surfactant & 3 & 5.6 & 10 & 27.8 & $0.005^{* *}$ \\
\hline 3.Asphyxia & 2 & 3.7 & 1 & 2.8 & 1.000 \\
\hline 4.Multiple births & 7 & 12.9 & 5 & 13.9 & 1.000 \\
\hline 5.Hyper bil & 24 & 44.4 & 22 & 61.1 & 0.137 \\
\hline 6.Photo & 24 & 44.4 & 22 & 61.1 & 0.137 \\
\hline 7.Sepsis & 17 & 31.4 & 18 & 50.0 & 0.122 \\
\hline 8.Apnoea & 4 & 7.4 & 7 & 19.4 & 0.108 \\
\hline 9.Anemia & 5 & 9.2 & 7 & 19.4 & 0.210 \\
\hline 10.PDA & 2 & 3.7 & 6 & 16.7 & $0.056+$ \\
\hline 11.NEC & 5 & 9.2 & 2 & 5.6 & 0.698 \\
\hline 12.Shock & 3 & 5.6 & 5 & 13.9 & 0.258 \\
\hline 13.Hypogly & 2 & 3.7 & 2 & 5.6 & 1.000 \\
\hline
\end{tabular}

\section{Table 3: Correlation of neonatal complications with incidence of ROP}

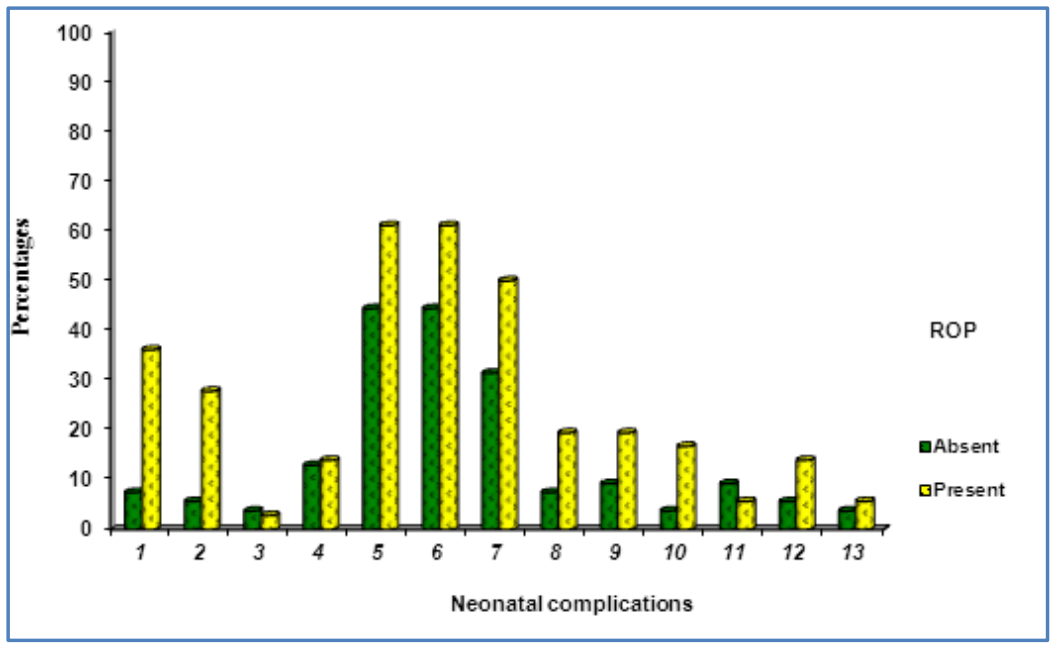

DISCUSSION: Retinopathy of prematurity is an avoidable cause of childhood blindness and its control is given priority in WHO's VISION 2020 programme.

INCIDENCE: The overall incidence of ROP in the present study 40\%. Various Indian studies had reported overall incidence ranging from $17.5 \%$ to $51.9 \%$ and International studies ranging from $10.0 \%$ to $45.4 \%$. This was in agreement with Maheshwari et al ${ }^{12}$ and Rekha ${ }^{13}$ et al studies.

RISK FACTORS: In our study gestational age, birth weight, oxygen administration, RDS, surfactant therapy, PDA were found to be the risk factors. 
GESTATIONAL AGE: Correlation of gestational age with ROP is inversely proportional as evident from the various studies conducted worldwide. Highest incidence of ROP in the present study is found among the babies with the gestational age range between $32-34$ weeks that is $40 \%$. Among ROP babies Mean Gestational Age by dates of babies with stage 1 disease is $33.33+2.87$ weeks, stage 2 disease is $31.81 \pm 2.67$ weeks, stage 3 disease is $30.00 \pm 3.46$ weeks with a significant p value $0.001^{* *}$

BIRTH WEIGHT: ROP incidence and severity increases as birth weight decreases. In our study Birth weight of ROP babies ranged from $700 \mathrm{~g}$ to $2500 \mathrm{~g}$ with a mean birth weight $1470.28 \pm 304.21 \mathrm{~g}$ with a significant $\mathrm{p}$ value of $0.001^{* *}$ this is in agreement with Charan et al ${ }^{10}$, Dogra et al. ${ }^{10}$ Studies.

OXYGEN THERAPY: In present study oxygen administration is a significant risk factor for development of ROP ( $p=0.041$ ). But not an independent risk factor on multivariate analysis. This is in agreement with Gupta et al and Rekha et al studies.

RDS: RDS is a significant risk factor for development of ROP. In present study it is an independent risk factor for development of ROP on multivariate analysis ( $\mathrm{p}=0$.). Of 23 babies who had RDS in the study group, 8 (34.8\%) developed ROP which is in comparison with Gupta et al studies.

PDA: In our study among ROP babies, 6 babies (16.7\%) had PDA with p value $0.056+$ which is significant. The study conducted in New South Wales, Australia revealed that ROP was seen in 79\% of infants with PDA and 24\% had severe involvement.

CONCLUSION: The present study highlights the magnitude of the problem due to ROP in a tertiary care center.

Gestational age ( $<37$ weeks) and Low birth weight $(2500 \mathrm{~g})$ are important risk factors for ROP.

Screening should be intensified in the presence of factors like RDS, oxygen administration and exchange transfusion.

Timely referral of detected ROP cases for early treatment prevents blindness.

There is need for the obstetricians, neonatologist and ophthalmologist to work in close cooperation to prevent blindness due to ROP.

\section{REFERENCES:}

1. Coats DK, Miller AM, Hussein MA, McCreery KM, Holz E, Paysse EA. Involution of Retinopathy of Prematurity after Laser Treatment: Factors Associated with Development of Retinal Detachment. Am J Ophthalmol. 2005; 140:214-22.

2. Fanaroff AA, Martin RJ, editors. 7th ed. Louis: Mosby; 2002. Neonatal Perinatal Medicine; pp. 676-745.

3. Azad R, Chandra P. Retinopathy of prematurity. J Indian Med Assoc.2005; 103:370-2.

4. Kim TI, Sohn J, Pi SY, Yoon YH. Postnatal risk factors of retinopathy of prematurity. Paediatr Perinat Epidemiol. 2004; 18:130-4.

5. Shah VA, Yeo CL, Ling YL, Ho LY. Incidence, risk factors of retinopathy of prematurity among very low birth weight infants in Singapore. Ann Acad Med Singapore. 2005; 34:169-78. 
6. Gupta VP, Dhaliwal U, Sharma R, Gupta P, Rohatgi J. Retinopathy of prematurity-risk factors. Indian J Pediatr. 2004; 71:887-92.

7. Karna P, Muttineni J, Angell L, Karmaus W. Retinopathy of prematurity and risk factors: A prospective cohort study. BMC Pediatr. 2005; 5:18.

8. Englert JA, Saunders RA, Purohit D, Hulsey TC, Ebeling M. The effect of anemia on retinopathy of prematurity in extremely low birth weight infants. J Perinatol. 2001; 21:21-6.

9. Akkoyun I, Oto S, Yilmaz G, Gurakan B, Tarcan A, Anuk D, Akgun S, et al. Risk factors in the development of mild and severe retinopathy of prematurity. J AAPOS. 2006; 10:449-53.

10. Charan R, Dogra MR, Gupta A, Narang A. The incidence of retinopathy of prematurity in a neonatal care unit. Indian J Opthalmol 1995; 43: 123-126.

11. Rekha S, Battu RR. Retinopathy of prematurity: incidence and risk factors. Indian Pediatrics 1996; 33: 999-1003.

12. Maheshwari R, Kumar H, Paul VK, Singh M, Deorari AK, Tiwari AK. Incidence and risk factors of retinopathy of prematurity in a tertiary care newborn unit in New Delhi. Natl Med J Ind 1996; 9(5): 211-214.

\section{AUTHORS:}

1. Sneha R.

2. Poornima Shankar

\section{PARTICULARS OF CONTRIBUTORS:}

1. Senior Resident, Department of Paediatrics, Kempegowda Institute of Medical Science and Research Centre.

2. Associate Professor, Department of Paediatrics, Kempegowda Institute of Medical Science and Research Centre.

\section{NAME ADDRESS EMAIL ID OF THE CORRESPONDING AUTHOR:}

Dr. Sneha R, \#90, 34 ${ }^{\text {th }}$ Cross, $2^{\text {nd }}$ Block,

Rajajinagar, Bangalore - 560010.

E-mail: snehajini@gmail.com

Date of Submission: 07/02/2014.

Date of Peer Review: 08/02/2014.

Date of Acceptance: 19/02/2014.

Date of Publishing: 06/03/2014. 